\title{
Call for Papers, Issue 3/2022
}

\section{Sustainable Autonomous Systems}

\author{
Roman Beck • Jens Dibbern • Martin Wiener
}

Published online: 30 September 2020

(c) Springer Fachmedien Wiesbaden GmbH, ein Teil von Springer Nature 2020

\section{Special Issue}

The ongoing digital transformation is challenging the way business is conducted and how value is created and captured. While prior digitalization waves focused on replacing paper as physical carrier of information, leveraging the Internet as global communication infrastructure, and developing reactive, partly automated business processes and systems (e.g., Legner et al. 2017), the next wave will be about transforming these processes/systems into proactive sustainable autonomous systems (SAS). Such SAS are characterized by complex "systems of systems" of different age, quality, reliability, and performance, which may develop their own dynamics. A unique characteristic of SAS is their reliance on large amounts of data, along with the use of advanced technologies - such as the Internet of Things, Artificial Intelligence, or Blockchain-that allow for gathering and processing 'big' data with limited, or even no, human involvement. Even though SAS are designed, developed, and implemented in a process of socio-technical interaction; once in use, they take on the role of agents that make decisions and perform actions

\footnotetext{
R. Beck

Business IT Department, IT University of Copenhagen, Copenhagen, Denmark

e-mail: beck@itu.dk

J. Dibbern $(\bowtie)$

Institute of Information Systems, Information Engineering, University of Bern, Bern, Switzerland

e-mail: jens.dibbern@iwi.unibe.ch

\section{Wiener}

Chair of Business Informatics, Esp. Business Engineering, TU

Dresden, Dresden, Germany

e-mail: martin.wiener@tu-dresden.de
}

independently of humans. In other words, what has been created in a socio-technical way by implementing patterns-including organizational rules, as well as social norms and values - into a technical system, turns into a techno-social system once operating, where social actors in the organizational environment respond to the technical system and where the system may self-adapt to environmental changes. Thus, agency, decision rights, and responsibility are handed over to autonomous systems, while the ultimate accountability and decision rights to change the systems may still reside with the governing entity owning those systems.

By now, SAS can be found in various fields of application. Popular examples include driverless cars, smart cities, and smart homes, which often rely on a combination of sensors, algorithms, and self-executable code. Besides these tangible SAS, we note a growing number of intangible SAS in the form of software systems that operate either entirely in the background or at the interface with humans. Examples are intelligent chatbots and recommender systems, as well as algorithmic management and control systems, such as the ones used by Uber and other gig economy firms to control the behaviors of their digital workforce (e.g., Kellogg et al. 2020).

Autonomous systems, however, do not only differ in terms of application areas and contexts, but also in terms of their temporal dimension, as captured by the notion of sustainability, which generally refers to some long-term existence. This means that, once in use, SAS should be able to exist and fulfill their function for some time without further human interaction. In this sense, sustainability may refer to self-learning systems that are constantly improving themselves, such as an autonomous vehicle that, on a daily commute, keeps optimizing the route it takes. In doing so, the vehicle may also constantly improve its fuel 
consumption, which points to another perspective on sustainability directed toward the effects of SAS operation and use. As such, sustainability may also concern the long-term economic, social, and environmental effects of using autonomous systems (Hart and Milstein 2003), commonly referred to as the "3Ps" (profit, people, and planet) of the triple bottom line (Elkington 1997). This perspective includes the effects of SAS on the efficient use of tangible resources, such as energy (e.g., smart offices), space (e.g., smart cities), or food (e.g., smart fridges), as well as their effects on intangible resources, such as the longevity of data (e.g., for auditing purposes) or human and social capital in general. In addition, focusing on the sustainability of autonomous systems also demands the recognition of their limits. For example, given that such systems can be expected to come with unforeseen second-order or spillover effects, we may ask ourselves whether we really want to rely on systems that are on 'autopilot.' Also, critical ethical questions arise, for example, with regard to the decision rules according to which autonomous systems act (e.g., how a driverless car should react to unforeseen circumstances affecting humans).

\section{Invited Contributions}

With this call for papers, we seek to enhance our common understanding of the implications surrounding the design, development, and use of information systems that can be characterized by both autonomy and sustainability (i.e., SAS). Here, we acknowledge that neither autonomy nor sustainability are fixed end states, or ultimate goals, by which information systems should be evaluated. Rather, they represent information systems characteristics that need to be better understood as they appear in various forms and degrees, change over time, and have manifold consequences for individuals, organizations, and society.

The special issue focus on SAS leads to a number of important questions that can be fruitfully studied from a broad range of perspectives. As such, we encourage submissions from different methodological and theoretical perspectives-including different conceptions of causality (Markus and Rowe 2018) —-stemming from information systems, economics, organizational behavior, strategic management, software engineering, and others. In this regard, authors must clearly outline why they consider their study to be new and interesting for research and practice, as well as how it addresses the special issue theme. Also, while the theoretical and conceptual foundations may stem from neighboring disciplines, we expect clearly articulated contributions to information systems research.

In the following, to stimulate submissions, we put together a list of sample questions that may serve prospective authors as a source of inspiration; however, this list is meant to be neither exclusive nor exhaustive:

What goals drive the design, development, and use of SAS and what potential tensions and/or paradoxes can be associated with those goals? How do organizations create an effective balance between different sustainability goals? Under what conditions do they prioritize certain goals at the expense of other goals? How can SAS be designed to achieve a particular set of objectives and 'cushion' its inherent tensions? How can the implementation and use of SAS be controlled and governed? Who should be in charge of corresponding control and governance activities? As well, designing and developing SAS from an end-to-end point of view may require novel and mindful systems engineering, evaluation, and testing approaches that go beyond traditional ones; if so, how would such approaches look like; who would approve them; and what criteria or requirements would have to be met to ensure the proper functioning of SAS along with their seamless integration into existing structures? How can interdependencies among different SAS be managed in due consideration of sustainability? If the development of SAS was outsourced to third-party vendors, who would ensure their adaptation to environmental changes and how would this process be governed? How should network and/or platform-based organizations-whose operations and business models tend to be based on the use of algorithmic systems-be governed and regulated with respect to sustainability goals? What about the ethical dilemmas and issues arising from algorithmic decision-making and how can managers, organizations, and society cope with those dilemmas/issues? What are the limitations of SAS and how can their appropriate use be influenced by a societal discourse? What level of digital maturity and what dynamic capabilities are needed for the value-enhancing use of SAS? Etc.

\section{Submission Guidelines}

The submission deadline is 28 February 2021. All manuscripts should be submitted through the journal's online submission system (https://www.editorialmanager.com/ buis/). Please observe the instructions on manuscript formatting and length. Submission guidelines and general author guidelines are available under: https://www.bisejournal.com/author_guidelines.

Each submission will be reviewed anonymously (double-blind process) by at least two referees with respect to its relevance, originality, and research quality. In addition to the editors of the special issue, distinguished international scholars will be involved in the review process as associate editors. 


\section{Schedule}

Initial paper submission deadline: 28 February 2021. First round authors notification: 15 June 2021. Invited revisions deadline: 31 August 2021.

Second round authors notification: 15 November 202. Final revision deadline: 31 January 2022.

Final authors notification: 15 February 2022.

Projected publication: June 2022.

\section{Associate Editors}

Alexander Benlian, TU Darmstadt. Jens Förderer, TU Munich.

Robert Gregory, University of Virginia.

Thomas Huber, ESSEC Business School, Paris.

Oliver Krancher, IT University of Copenhagen.

Thomas Kude, ESSEC Business School.

Stefan Morana, Saarland University.

Esko Penttinen, Aalto University.

Ulrich Remus, University of Innsbruck.
Marten Risius, University of Queensland.

Nils Urbach, University of Bayreuth.

Tim Weitzel, University of Bamberg.

Till Winkler, Copenhagen Business School.

\section{References}

Elkington J (1997) Cannibals with forks: the triple bottom line of 21st century business. Capstone, Oxford

Hart SL, Milstein MB (2003) Creating sustainable value. Acad Manag Exec 17(2):56-67

Kellogg KC, Valentine M, Christin A (2020) Algorithms at work: the new contested terrain of control. Acad Manag Ann 14(1):366-410

Legner C, Eymann T, Hess T, Matt C, Böhmann T, Drews P, Maedche A, Urbach N, Ahlemann F (2017) Digitalization: opportunity and challenge for the business and information systems engineering community. Bus Inf Syst Eng 59(4):301-308

Markus ML, Rowe F (2018) Is IT changing the world? Conceptions of causality for information systems theorizing. MIS Q 42(4):1255-1280 